\title{
Relationships between Mutant Prevention Concentrations and Mutation Frequencies against Enrofloxacin for Avian Pathogenic Escherichia coli Isolates
}

\author{
Manao OZAWA ${ }^{1) *}$ and Tetsuo ASAI ${ }^{1)}$ \\ 1)National Veterinary Assay Laboratory, Ministry of Agriculture, Forestry and Fisheries, 1-15-1 Tokura, Kokubunji, Tokyo 185-8511, Japan
}

(Received 23 March 2012/Accepted 28 December 2012/Published online in J-STAGE 18 January 2013)

\begin{abstract}
Clinical efficacies of mutant prevention concentration (MPC) and mutant selection window (MSW) hypotheses have been evaluated for human clinical isolates. We tested the MSW hypothesis by evaluating the relationships between MPCs and mutation frequencies against enrofloxacin for avian pathogenic Escherichia coli (APEC) isolates. Mutation frequencies of strains with MPC:MIC ratios of 8 to 16 were significantly higher than those of strains with an MPC:MIC ratio of 4. Mutation frequencies and MPCs of serogroup O2 strains were lower than those of the other strains; these results may correlate with the absence of fluoroquinolone-resistant $\mathrm{O} 2$ strains. Our results support the MSW hypothesis that the range of the MSW is involved in selection of resistant mutants.

KEY WORDS: antimicrobial susceptibility, avian pathogenic Escherichia coli, fluoroquinolone, mutant prevention concentration.
\end{abstract}

doi: 10.1292/jvms.12-0131; J. Vet. Med. Sci. 75(6): 709-713, 2013

Colibacillosis contributes to increased mortality and economic losses in the poultry industry worldwide. Avian pathogenic Escherichia coli (APEC) is the etiological agent of colibacillosis, which presents as a localized or systemic infection characterized by colisepticemia, coligranuloma, air sac disease, pericarditis or swollen head syndrome [4]. Although more than 180 serogroups of E. coli have been identified, $\mathrm{O} 1, \mathrm{O} 2$ and $\mathrm{O} 78$ are most frequently isolated from avian colibacillosis [4]. Treatment of colibacillosis primarily involves the use of approved antimicrobials such as $\beta$-lactams, aminoglycosides, tetracyclines, phenicols, antifolates such as sulfonamide and trimethoprim and fluoroquinolones. However, a high proportion of APEC strains have become resistant to these antimicrobial agents $[13,19$, 22]. In Japan, resistance to ampicillin has been observed most frequently $(77.1 \%)$, followed by resistance to oxytetracycline $(75.9 \%)$, kanamycin $(36.1 \%)$, fradiomycin $(33.7 \%)$, trimethoprim (25.3\%) and enrofloxacin (21.7\%) [17].

Fluoroquinolones have been used widely in human and veterinary medicine. Enrofloxacin is an antimicrobial that is generally used to treat avian colibacillosis in Japan. Excessive use (or misuse) of fluoroquinolones can cause the emergence of bacterial strains that are resistant to this drug; thus, the emergence of fluoroquinolone resistance has been reported worldwide [2, 9, 18, 21, 22]. In Japan, approximately $20 \%$ of APEC isolates were shown to be fluoroquinolone-resistant, and serogroups $\mathrm{O} 78, \mathrm{O} 8$, and untypable strains resistant to fluoroquinolone have been reported [17]. The major mechanism of fluoroquinolone resistance involves mutations in quinolone resistance-determining regions (QRDRs) in

*Correspondence to: Ozawa, M., National Veterinary Assay Laboratory, Ministry of Agriculture, Forestry and Fisheries, 1-15-1 Tokura, Kokubunji, Tokyo 185-8511, Japan.

e-mail: ozawa@nval.maff.go.jp

C2013 The Japanese Society of Veterinary Science
DNA-gyrase and topoisomerase IV. An increased number of mutations in the QRDRs of these enzymes correlate with the increase in MIC values against quinolones of E. coli [20].

Clinical efficacies of the mutant prevention concentration (MPC) and mutant selection window (MSW) hypotheses have been evaluated for human clinical isolates [6]. MSW is the antimicrobial concentration range at which emergence of fluoroquinolone-resistant mutants will develop [23]. The hypothesis suggests that maintaining drug concentrations above the MSW in blood during therapy can control the emergence of resistant strains. Prescriptions based on the MSW hypothesis may be useful for treating bacterial infections in animals. However, the hypothesis has not been tested in the veterinary field. The lower boundary of the MSW is the minimum inhibitory concentration (MIC), whereas the upper boundary is the mutant prevention concentration (MPC), an antibiotic concentration that allows no mutant growth [23]. MSW range may be correlated with mutant selection processes. However, a relationship between MSW range and mutant recovery has not been demonstrated experimentally. The aim of this study was to test the MSW hypothesis by evaluating relationships between MPCs and mutation frequencies against enrofloxacin in APEC isolates.

\section{MATERIALS AND METHODS}

Bacterial strains: From 2001 to 2007, a total of 127 E. coli strains were isolated from chickens ( 1 isolate per chicken) diagnosed with colibacillosis in Japan. These strains have been investigated in our previous studies $[16,17]$. The MIC range of enrofloxacin for these strains is $0.03-128 \mu \mathrm{g} / \mathrm{ml}$ (breakpoint, $2 \mu \mathrm{g} / \mathrm{m} l$ ). Of the 127 strains, 71 were serotyped using previously described methods [17]. Of these 71 strains, those with MIC values of $0.03 \mu \mathrm{g} / \mathrm{m} l$ for enrofloxacin (22 strains total; O78, 10 strains; O2, 7 strains; O18, 2 strains; O1, 1 strain; O8, 1 strain; O55, 1 strain), were used in this study. These strains were isolated from randomly selected 
chicken farms in Japan (Hokkaido/Tohoku district, 2 strains; Kanto/Koshinetsu district, 2 strains; Tokai/Hokuriku district, 3 strains; Kinki district, 6 strains; Chugoku/Shikoku district, 7 strains; Kyushu district, 2 strains). All isolates originated from nonalimentary tissues, such as the heart, liver, kidney, spleen, brain and articular cavity. Isolates were confirmed as E. coli by using the API-20E Bacterial Identification System (bioMerieux, Durham, NC, U.S.A.) and stored in 10\% sterile skim milk at $-80^{\circ} \mathrm{C}$.

Antimicrobial susceptibility tests: MICs of enrofloxacin were determined using an agar dilution method in the presence or absence of $20 \mathrm{mg} / \mathrm{l}$ of Phe-Arg- $\beta$-naphthylamide (Sigma, St. Louis, MO, U.S.A.), an efflux pump inhibitor, according to the guidelines of the Clinical and Laboratory Standards Institute [3]. Escherichia coli ATCC 25922, Staphylococcus aureus ATCC 29213, Pseudomonas aeruginosa ATCC 27853 and Enterococcus faecalis ATCC 29212 were used as controls during MIC determination.

Mutation frequencies and MPCs: Strains were cultured in Mueller-Hinton broth for $18 \mathrm{hr}$. The suspension was centrifuged and resuspended in Mueller-Hinton broth to yield a concentration of $10^{10}$ colony-forming units $(\mathrm{CFU}) / \mathrm{ml}$, and then $>10^{9}$ CFU was plated onto each of 5 plates supplemented with diluted enrofloxacin $(2-16 \times$ MIC). Suspensions of each isolate were also plated onto nonselective agars to monitor the number of bacterial cells that grew on the plates. The plates were incubated at $37^{\circ} \mathrm{C}$ for $24 \mathrm{hr}$. Mutation frequency was determined as the ratio of the average number of colonies that emerged on the plates containing $0.06 \mu \mathrm{g} / \mathrm{m} l$ enrofloxacin divided by the average viable counts on drugfree plates. MPC was recorded as the lowest concentration of antimicrobial agent that prevented mutant emergence [5].

Isolation of enrofloxacin-resistant mutants: Spontaneous enrofloxacin-resistant mutants were isolated from several $E$. coli strains used in this study. Mutants grown on agar plates containing $0.06 \mu \mathrm{g} / \mathrm{m} l$ of enrofloxacin were inoculated into Mueller-Hinton broth and incubated for $18 \mathrm{hr}$. The suspension was centrifuged and resuspended in Mueller-Hinton broth to yield a concentration of $10^{10} \mathrm{CFU} / \mathrm{ml}$, and then $>10^{9}$ CFU was plated onto agar plates containing a two-fold concentration of enrofloxacin. Selection was continued to obtain a concentration of $1 \mu \mathrm{g} / \mathrm{m} l$ of enrofloxacin.

Sequencing of gyrA and parC: QRDRs of the gyrA and parC genes were amplified using PCR as previously described [7]. PCR products were purified using the QIAquick PCR purification kit (QIAGEN, Hilden, Germany) and sent to FASMAC Co., Ltd. (Atsugi, Japan) for DNA sequencing. Dye terminator cycle sequencing was performed using the BigDye Terminator v3.1 Cycle Sequencing Kit and 3730xl DNA Analyzer (Applied Biosystems, Foster City, CA, U.S.A.). The sequences were compared with those previously reported for gyrA (GenBank accession number X06373) and parC (M58408).

Statistical analysis: Statistical significance of the difference in geometric mean mutation frequency was determined using Wilcoxon's rank-sum test. A statistical difference of $P<0.05$ was considered significant.

\section{RESULTS}

MPC:MIC ratio and mutation frequency: Table 1 shows the MICs, MPCs and the MPC:MIC ratio in relation to mutation frequencies. Mutation frequencies of the strains with MPC:MIC ratios of 8-16 were significantly higher than those of strains with an MPC:MIC ratio of $4(P<0.001)$.

Mutation frequency of $\mathrm{O} 2$ strains was significantly lower than that of 078 strains and that of strains belonging to the serogroups other than $\mathrm{O} 78$ and $\mathrm{O} 2$ (Fig. 1).

Effect of efflux pump inhibitor on MIC values: MIC values of enrofloxacin in the presence of the inhibitor ranged from 0.007 to $0.015 \mu \mathrm{g} / \mathrm{m} l$. Only a minimal difference was observed for the change in MIC between strains with MPC:MIC ratios of 8-16 and strains with MPC:MIC ratios of $2-4$.

Amino acid change in QRDRs of GyrA and ParC: The gyrA gene from 2 independent mutants (derived from strain ID $17-3$ or $14-26$ ) emerged on plates containing $0.06 \mu \mathrm{g} /$ $\mathrm{m} l$ enrofloxacin was sequenced to verify the mutations in the gyrA gene. These strains contained the substitutions Asp $87 \rightarrow$ Gly $($ GAC $\rightarrow$ GGC) or Ala84 $\rightarrow$ Pro $(\mathrm{GCG} \rightarrow \mathrm{CCG})$ in GyrA.

The result of codon changes in the QRDRs of gyrA and parC in spontaneous mutants indicated that $\mathrm{O} 78$ strains possessed point mutations in codon 87 of gyr $A$ and codon 80 of $\operatorname{parC}$ (Table 2). $\mathrm{O} 2$ strains contained point mutations in codon 83 or 87 of gyr $A$, but showed no point mutations in $\operatorname{parC}$.

\section{DISCUSSION}

The MSW hypothesis has been evaluated using in vitro dynamic models and in vivo animal models [6]; however, the relationship between MSW range and emergence of resistant strains is not clear. In this study, we examined the relationships between MSW range and mutation frequencies against enrofloxacin for APEC isolates.

Li et al. [12] reported that strains containing point mutations in the QRDR of gyrA with an MPC:MIC ratio of 16 showed higher mutation frequencies than did strains with MPC:MIC ratios of 2-4. Therefore, we examined the relationship between mutation frequency and MPC:MIC ratio. We compared mutation frequencies of strains with an MPC:MIC ratio of 4 to those of strains with MPC:MIC ratios of 8-16. The results indicated that mutation frequencies of strains with MPC:MIC ratios of 8-16 were significantly higher than those of strains with an MPC:MIC ratio of 4. These results support the observation that MSW range is involved in resistant mutant selection [23]. However, there are some limitations to our study. The reason for the link between MSW range and mutation frequency could not be determined due to the relatively small number of strains analyzed in this study.

MPC values of strains tested varied from $0.06-0.50 \mu \mathrm{g} /$ $\mathrm{m} l$. Typical mechanisms of fluoroquinolone resistance include mutations in QRDRs, upregulation of an intrinsic efflux system and a decrease in cell permeability [20]. APEC 
Table 1. Minimum inhibitory concentrations (MIC), mutation prevention concentrations (MPC) and the MPC:MIC ratio in relation to mutation frequencies for avian pathogenic Escherichia coli strains

\begin{tabular}{|c|c|c|c|c|c|c|c|}
\hline \multirow[b]{2}{*}{ Strains } & \multirow[b]{2}{*}{ Serogroups } & \multicolumn{2}{|c|}{ Enrofloxacin $\mathrm{MIC}^{*}(\mu \mathrm{g} / \mathrm{m} l)$} & \multirow{2}{*}{$\begin{array}{c}\mathrm{MPC} \\
(\mu \mathrm{g} / \mathrm{m} l)\end{array}$} & \multirow[b]{2}{*}{ MPC:MIC ratio } & \multicolumn{2}{|c|}{ Mutation frequencies } \\
\hline & & $\begin{array}{l}\text { Without } \\
\text { inhibitor }\end{array}$ & $\begin{array}{c}\text { With } \\
\text { inhibitor }\end{array}$ & & & & geomean $^{* *}$ \\
\hline $19-12$ & $\mathrm{O} 78$ & 0.03 & 0.015 & 0.5 & 16 & $4.49 \times 10^{-9}$ & \\
\hline $19-17$ & $\mathrm{O} 78$ & 0.03 & 0.015 & 0.5 & 16 & $6.35 \times 10^{-9}$ & \\
\hline $18-38$ & $\mathrm{O} 78$ & 0.03 & 0.015 & 0.25 & 8 & $1.52 \times 10^{-8}$ & \\
\hline $18-39$ & $\mathrm{O} 78$ & 0.03 & 0.015 & 0.25 & 8 & $7.32 \times 10^{-9}$ & $6.65 \times 10^{-9}$ a) \\
\hline $14-26$ & $\mathrm{O} 78$ & 0.03 & 0.015 & 0.25 & 8 & $3.32 \times 10^{-9}$ & \\
\hline $18-21$ & $\mathrm{O} 1$ & 0.03 & 0.015 & 0.25 & 8 & $3.26 \times 10^{-8}$ & \\
\hline $17-6$ & O8 & 0.03 & 0.007 & 0.25 & 8 & $1.68 \times 10^{-9}$ & \\
\hline $17-1$ & O78 & 0.03 & 0.015 & 0.125 & 4 & $4.68 \times 10^{-10}$ & \\
\hline $17-5$ & $\mathrm{O} 78$ & 0.03 & 0.015 & 0.125 & 4 & $2.67 \times 10^{-10}$ & \\
\hline $16-36$ & $\mathrm{O} 78$ & 0.03 & 0.015 & 0.125 & 4 & $1.85 \times 10^{-9}$ & \\
\hline $17-13$ & $\mathrm{O} 78$ & 0.03 & 0.015 & 0.125 & 4 & $1.01 \times 10^{-9}$ & \\
\hline $17-21$ & $\mathrm{O} 2$ & 0.03 & 0.015 & 0.125 & 4 & $3.12 \times 10^{-10}$ & \\
\hline $19-14$ & $\mathrm{O} 2$ & 0.03 & 0.015 & 0.125 & 4 & $6.9 \times 10^{-10}$ & \\
\hline $14-2$ & $\mathrm{O} 2$ & 0.03 & 0.015 & 0.125 & 4 & $2.48 \times 10^{-9}$ & $7.87 \times 10^{-10 b)}$ \\
\hline $19-2$ & $\mathrm{O} 2$ & 0.03 & 0.007 & 0.125 & 4 & $3.68 \times 10^{-10}$ & \\
\hline $19-3$ & $\mathrm{O} 2$ & 0.03 & 0.007 & 0.125 & 4 & $3.19 \times 10^{-10}$ & \\
\hline $17-3$ & $\mathrm{O} 2$ & 0.03 & 0.015 & 0.125 & 4 & $2.45 \times 10^{-10}$ & \\
\hline $19-24$ & O18 & 0.03 & 0.007 & 0.125 & 4 & $5.49 \times 10^{-9}$ & \\
\hline $18-35$ & $\mathrm{O} 18$ & 0.03 & 0.015 & 0.125 & 4 & $1.15 \times 10^{-9}$ & \\
\hline $17-2$ & O55 & 0.03 & 0.015 & 0.125 & 4 & $1.97 \times 10^{-9}$ & \\
\hline $17-14$ & O78 & 0.03 & 0.007 & 0.06 & 2 & 0 & \\
\hline $17-19$ & $\mathrm{O} 2$ & 0.03 & 0.015 & 0.06 & 2 & 0 & - \\
\hline
\end{tabular}

* The enrofloxacin MIC was determined in the absence and presence of $20 \mathrm{mg} / \mathrm{l}$ of Phe-Arg- $\beta$-naphthylamide. ** Values followed by different letters are significantly different $(P<0.05)$.

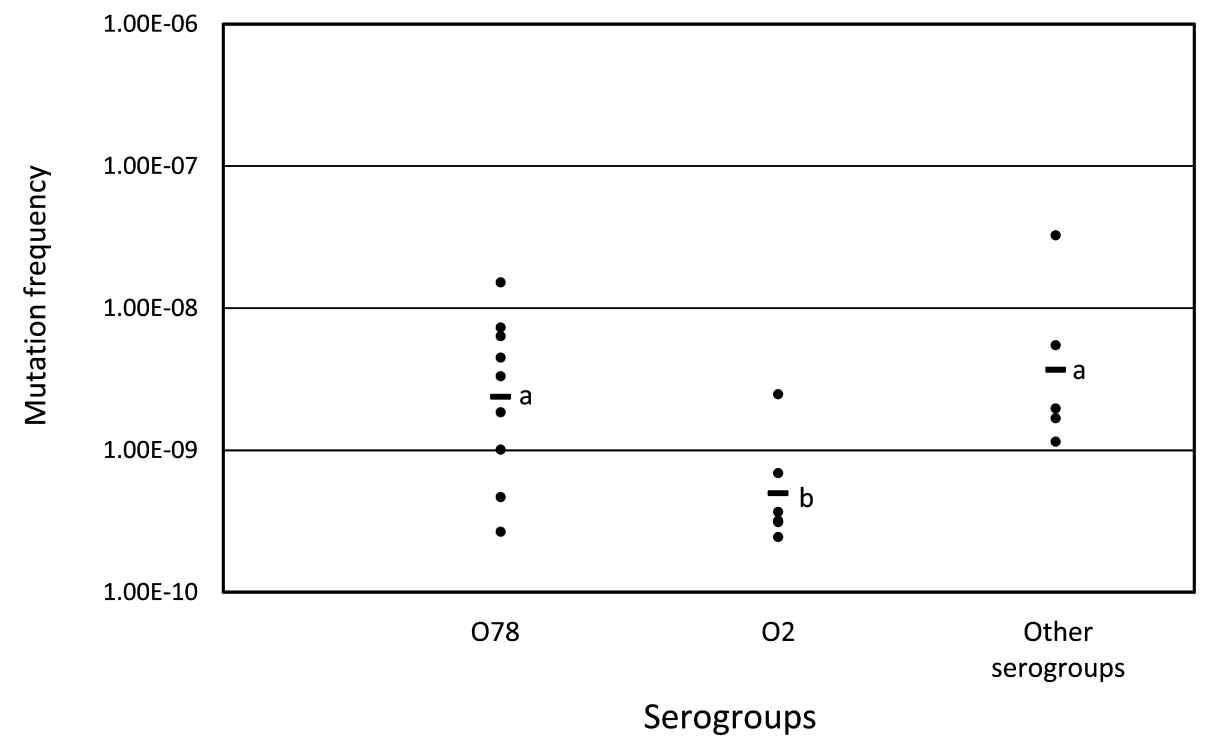

Fig. 1. Mutation frequencies in APEC strains against enrofloxacin. Each data point represents the mutation frequency of 1 bacterial species. The geometric mean mutation frequency for each serogroup is indicated by a line. Values followed by different letters are significantly different $(P<0.05)$. 
Table 2. Amino acid changes in the QRDRs of GyrA and ParC of spontaneous mutants

\begin{tabular}{|c|c|c|c|c|}
\hline \multirow{3}{*}{ Strains } & \multirow{3}{*}{ Serogroups } & \multicolumn{3}{|c|}{ Amino acid change (codon change) ${ }^{*}$} \\
\hline & & \multicolumn{2}{|c|}{ GyrA } & \multirow{2}{*}{$\begin{array}{c}\text { ParC } \\
80\end{array}$} \\
\hline & & 83 & 87 & \\
\hline Wild Type & - & Ser(TCG) & Asp(GAC) & $\operatorname{Ser}(\mathrm{AGT})$ \\
\hline $17-1$ & $\mathrm{O} 78$ & $\mathrm{WT}^{* *}$ & Tyr(TAC) & Ser(AGC) \\
\hline $16-36$ & $\mathrm{O} 78$ & WT & $\operatorname{Tyr}(\mathrm{TAC})$ & Ser(AGC) \\
\hline $18-39$ & $\mathrm{O} 78$ & WT & Gly(GGC) & $\operatorname{Ser}(A G C)$ \\
\hline $14-26$ & $\mathrm{O} 78$ & WT & $\operatorname{Tyr}(\mathrm{TAC})$ & WT \\
\hline $17-13$ & $\mathrm{O} 78$ & WT & WT & Ser(AGC) \\
\hline $14-2$ & $\mathrm{O} 2$ & Leu(TTG) & WT & WT \\
\hline $17-5$ & $\mathrm{O} 2$ & Leu(TTG) & WT & WT \\
\hline $17-19$ & $\mathrm{O} 2$ & Leu(TTG) & WT & WT \\
\hline $19-14$ & $\mathrm{O} 2$ & Leu(TTG) & WT & WT \\
\hline $17-3$ & $\mathrm{O} 2$ & WT & Gly(GGC) & WT \\
\hline
\end{tabular}

* Ser, serine; Asp, aspartic acid; Tyr, tyrosine; Gly, glycine; Leu, leucine. $* *$ Wild type.

strains used in this study were estimated to contain no mutations in QRDRs based on the MIC value of enrofloxacin. Therefore, mechanisms influencing MPC values of each APEC strain may include cell permeability or efflux pumps. An evaluation of the effect of the efflux pump inhibitor PheArg- $\beta$-naphtylamide on MIC values of enrofloxacin indicates little difference in the change in MIC values regardless of MPC:MIC ratios. Therefore, variation in MPC values may not be related to efflux pumps.

Interestingly, the fluoroquinolone-resistant serogroup $\mathrm{O} 2$ strain was not observed in either this study or in our previous study [17]. In China, the rate of resistance against enrofloxacin is high (90\%), and $\mathrm{O} 2$ strains were not isolated [21]. The mutation frequency of $\mathrm{O} 2$ strains was significantly lower than that of other strains in this study, and the MPC:MIC values of $\mathrm{O} 2$ strains (range, 2-4) indicated a lower tendency than those of other strains (range, 2-16). Amino acid substitutions in ParC are generally associated with the emergence of highly fluoroquinolone-resistant strains $[14,16]$. Spontaneous mutations in the parC gene were not found in $\mathrm{O} 2$ strains analyzed in this study, implying that $\mathrm{O} 2$ strains experience difficulty in acquiring parC mutations. However, strains must be compared between before and after enrofloxacin use in the same chicken to confirm the difficulty in acquiring parC mutations in $\mathrm{O} 2$ strains. The absence of fluoroquinolone-resistant $\mathrm{O} 2$ strains may be due to the low MPC value, low mutation frequency or the difficulty of incorporating mutations in parC.

Mutations related to antimicrobial resistance are often associated with reduced bacterial fitness [15]. If a mutant has a lower level of fitness than wild-type, it will be eliminated from the bacterial population. Marcusson et al. [14] reported that the parC mutation is associated with improved fitness and reduced susceptibility to fluoroquinolone. However, our results suggest that $\mathrm{O} 2$ strains have difficulty in acquiring $\operatorname{par} C$ mutations. In Japan, enrofloxacin was first approved to treat avian colibacillosis in 1991; the isolation frequency of serogroup O2 strains was $23.2 \%$ in the 1980 s [8] and $9.6 \%$ in the 2000s [17]. Similarly, Li et al. [11] reported that the isolation frequency of $\mathrm{O} 2$ strains was $32.4 \%$ in the $1990 \mathrm{~s}$ and $16.8-19.6 \%$ in the $2000 \mathrm{~s}$ in China. These data and our results showing that $\mathrm{O} 2$ strains have low MPC values, low mutation frequencies and difficulty in acquiring $\operatorname{parC}$ mutations suggest that the population of $\mathrm{O} 2$ strains has been decreased through the use of fluoroquinolones in the treatment of avian colibacillosis.

When treating avian colibacillosis, the MSW hypothesis should be considered. For most enrofloxacin-susceptible isolates, it is possible to achieve concentrations of enrofloxacin greater than their MPCs at the infection site. However, MPC values of mutant strains exceed the $\mathrm{C}_{\max }$ of enrofloxacin $(1.88-2.44 \mu \mathrm{g} / \mathrm{m} l)$ in chickens $[1,10,12]$. APEC strains possessing at least 1 mutation in QRDRs account for $57.4 \%$ of APEC strains [16]. Therefore, careless use of enrofloxacin can select for more highly resistant strains.

In conclusion, our results suggested a correlation between the MSW range and mutant strain emergence. Moreover, our results suggest that strains with a narrow MSW for enrofloxacin have been decreased through the use of fluoroquinolones. Thus, our results support the MSW hypothesis.

ACKNOWLEDGMENT. We are grateful to the staff of the Livestock Hygiene Service Centers across Japan for providing E. coli strains.

\section{REFERENCES}

1. Anadon, A., Martinez-Larranaga, M. R., Diaz, M. J., Bringas, P., Martinez, M. A., Fernandez-Cruz, M. L., Fernandez, M. C. and Fernandez, R. 1995. Pharmacokinetics and residues of enrofloxacin in chickens. Am. J. Vet. Res. 56: 501-506. [Medline]

2. Bywater, R., Deluyker, H., Deroover, E., de Jong, A., Marion, H., McConville, M., Rowan, T., Shryock, T., Shuster, D., Thomas, V., Vallé, M. and Walters, J. 2004. A European survey of antimicrobial susceptibility among zoonotic and commensal bacteria isolated from food-producing animals. J. Antimicrob. Chemother. 54: 744-754. [Medline] [CrossRef]

3. Clinical and Laboratory Standards Institute. 2007. Performance Standards for Antimicrobial Susceptibility Testing; Seventeenth Informational Supplement, M100-S17 Vol.27 No.1, Clinical and Laboratory Standards Institute, Wayne.

4. Dho-Moulin, M. and Fairbrother, J. M. 1999. Avian pathogenic Escherichia coli (APEC). Vet. Res. 30: 299-316. [Medline]

5. Drlica, K. 2003. The mutant selection window and antimicrobial resistance. J. Antimicrob. Chemother. 52: 11-17. [Medline] [CrossRef]

6. Drlica, K. and Zhao, X. 2007. Mutant selection window hypothesis updated. Clin. Infect. Dis. 44: 681-688. [Medline] [CrossRef]

7. Everett, M. J., Jin, Y. F., Ricci, V. and Piddock, L. J. 1996. Contributions of individual mechanisms to fluoroquinolone resistance in 36 Escherichia coli strains isolated from humans and animals. Antimicrob. Agents Chemother. 40: 2380-2386. [Medline]

8. Ike, K., Kume, K., Kawahara, K. and Danbara, H. 1990. Serotyping of o and pilus antigens of Escherichia coli strains isolated from chickens with coli-septicemia. Nihon Juigaku Zasshi 52: 1023-1027. [Medline] [CrossRef]

9. Kang, H. Y., Jeong, Y. S., Oh, J. Y., Tae, S. H., Choi, C. H., 
Moon, D. C., Lee, W. K., Lee, Y. C., Seol, S. Y., Cho, D. T. and Lee, J. C. 2005. Characterization of antimicrobial resistance and class 1 integrons found in Escherichia coli isolates from humans and animals in Korea. J. Antimicrob. Chemother. 55: 639-644. [Medline] [CrossRef]

10. Knoll, U., Glunder, G. and Kietzmann, M. 1999. Comparative study of the plasma pharmacokinetics and tissue concentrations of danofloxacin and enrofloxacin in broiler chickens. J. Vet. Pharmacol. Ther. 22: 239-246. [Medline] [CrossRef]

11. Li, L., Jiang, Z. G., Xia, L. N., Shen, J. Z., Dai, L., Wang, Y., Huang, S. Y. and Wu, C. M. 2010. Characterization of antimicrobial resistance and molecular determinants of beta-lactamase in Escherichia coli isolated from chickens in China during 19702007. Vet. Microbiol. 144: 505-510. [Medline] [CrossRef]

12. Li, Q., Bi, X., Diao, Y. and Deng, X. 2007. Mutant-prevention concentrations of enrofloxacin for Escherichia coli isolates from chickens. Am. J. Vet. Res. 68: 812-815. [Medline] [CrossRef]

13. Li, X. S., Wang, G. Q., Du, X. D., Cui, B. A., Zhang, S. M. and Shen, J. Z. 2007. Antimicrobial susceptibility and molecular detection of chloramphenicol and florfenicol resistance among Escherichia coli isolates from diseased chickens. J. Vet. Sci. 8: 243-247. [Medline] [CrossRef]

14. Marcusson, L. L., Frimodt-Moller, N. and Hughes, D. 2009. Interplay in the selection of fluoroquinolone resistance and bacterial fitness. PLoS Pathog. 5: e1000541. [Medline] [CrossRef]

15. Martinez, J. L. and Baquero, F. 2000. Mutation frequencies and antibiotic resistance. Antimicrob. Agents Chemother. 44: 1771-1777. [Medline] [CrossRef]

16. Ozawa, M., Baba, K., Shimizu, Y. and Asai, T. 2010. Comparison of in vitro activities and pharmacokinetics/pharmacodynamics estimations of veterinary fluoroquinolones against avian pathogenic Escherichia coli isolates. Microb. Drug Resist. 16:
327-332. [Medline] [CrossRef]

17. Ozawa, M., Harada, K., Kojima, A., Asai, T. and Sameshima, T. 2008. Antimicrobial susceptibilities, serogroups, and molecular characterization of avian pathogenic Escherichia coli isolates in Japan. Avian Dis. 52: 392-397. [Medline] [CrossRef]

18. Vandemaele, F., Vereecken, M., Derijcke, J. and Goddeerie, B. M. 2002. Incidence and antibiotic resistance of pathogenic Escherichia coli among poultry in Belgium. Vet. Rec. 151: 355-356. [Medline] [CrossRef]

19. Wang, X. M., Liao, X. P., Zhang, W. J., Jiang, H. X., Sun, J., Zhang, M. J., He, X. F., Lao, D. X. and Liu, Y. H. 2010. Prevalence of serogroups, virulence genotypes, antimicrobial resistance, and phylogenetic background of avian pathogenic Escherichia coli in south of China. Foodborne Pathog. Dis. 7: 1099-1106. [Medline] [CrossRef]

20. Webber, M. and Piddock, L. J. 2001. Quinolone resistance in Escherichia coli. Vet. Res. 32: 275-284. [Medline] [CrossRef]

21. Yang, H., Chen, S., White, D. G., Zhao, S., McDermott, P., Walker, R. and Meng, J. 2004. Characterization of multipleantimicrobial-resistant Escherichia coli isolates from diseased chickens and swine in China. J. Clin. Microbiol. 42: 3483-3489. [Medline] [CrossRef]

22. Zhao, S., Maurer, J. J., Hubert, S., De Villena, J. F., McDermott, P. F., Meng, J., Ayers, S., English, L. and White, D. G. 2005. Antimicrobial susceptibility and molecular characterization of avian pathogenic Escherichia coli isolates. Vet. Microbiol. 107: 215-224. [Medline] [CrossRef]

23. Zhao, X. and Drlica, K. 2001. Restricting the selection of antibiotic-resistant mutants: a general strategy derived from fluoroquinolone studies. Clin. Infect. Dis. 33: S147-S156. [Medline] [CrossRef] 